\title{
Article \\ Property Prediction of Ag-Filled Isotropic Conductive Adhesive through the Analysis of Its Curing and Decomposition Kinetics
}

\author{
Han Jiang ${ }^{1,2}$, Minbo Zhou ${ }^{1,2, *(\mathbb{D})}$ and Xinping Zhang ${ }^{1,2}$ \\ 1 School of Materials Science and Engineering, South China University of Technology, Guangzhou 510640, \\ China; msjianghan@mail.scut.edu.cn (H.J.); mexzhang@scut.edu.cn (X.Z.) \\ 2 Guangdong Provincial Engineering R\&D Center of Electronic Packaging Materials and Reliability, \\ South China University of Technology, Guangzhou 510640, China \\ * Correspondence: msmbzhou@scut.edu.cn
}

Citation: Jiang, H.; Zhou, M.; Zhang, X. Property Prediction of Ag-Filled Isotropic Conductive Adhesive through the Analysis of Its Curing and Decomposition Kinetics. Catalysts 2022, 12, 185. https:// doi.org/10.3390/catal12020185

Academic Editors: Shanthi Iyer and Lew Reynolds

Received: 31 December 2021

Accepted: 30 January 2022

Published: 1 February 2022

Publisher's Note: MDPI stays neutral with regard to jurisdictional claims in published maps and institutional affiliations.

Copyright: (C) 2022 by the authors. Licensee MDPI, Basel, Switzerland. This article is an open access article distributed under the terms and conditions of the Creative Commons Attribution (CC BY) license (https:// creativecommons.org/licenses/by/ $4.0 /)$.

\begin{abstract}
In this study, various thermal analyses were carried out on a self-developed and commerceoriented Ag-filled isotropic conductive adhesive (ICA) and its unfilled matrix resin through which glass transition temperature $\left(T_{g}\right)$ and thermal endurance could be quantitatively predicted. An autocatalyzed kinetic model was used to describe the curing reaction, which was proven to be in good consistency with the experimental data. The activation energies for the curing reaction of the ICA and the matrix resin were determined to be $68.1 \mathrm{~kJ} / \mathrm{mol}$ and $72.9 \mathrm{~kJ} / \mathrm{mol}$, respectively, which means that the reaction of the ICA was easier to occur than its unfilled matrix resin. As a result, the time-temperature profile could be calculated for any $T_{g}$ requested based on the kinetic model of curing and the DiBenedetto equation. Further, the thermal decomposition stability of the ICA and its unfilled matrix resin were also studied. The activation energies for the thermal decomposition of the ICA and the matrix resin were calculated to be $134.1 \mathrm{~kJ} / \mathrm{mol}$ and $152.7 \mathrm{~kJ} / \mathrm{mol}$, respectively, using the Ozawa-Flynn-Wall method, which means that the decomposition of ICA was easier to occur. The service life of the resin system at a specific temperature could therefore be calculated with their activation energy. The addition of micro-scale Ag flakes did not change the curing and decomposition mechanisms by much.
\end{abstract}

Keywords: isotropic conductive adhesive; Ag flakes; curing kinetics; decomposition kinetics; glass transition temperature

\section{Introduction}

Resin-based conductive adhesives have become widely used in many electronic packaging applications as interconnect materials, such as chip-on-glass and chip-on-flex, among which isotropic conductive adhesive (ICA) plays an increasingly important role [1]. ICA is a thermoset epoxy matrix impregnated with a certain amount of electrically conductive fillers, typically micro-scale silver flakes. During the packaging process, the resin is cured to simultaneously form the mechanical connection and provide a conducting medium for the electrical connection, thus the curing process of the adhesive significantly influences the ultimate electrical and mechanical properties of the electrically conductive interconnection [2]. Therefore, a deep understanding of the curing mechanisms and their effects on the properties of ICA is of great importance to the prediction and optimization of the curing processes (e.g., curing time and temperature) for the desired performance. Besides, ICA is often used in high-temperature applications such as ceramic substrates and chip components. As the decomposition of the matrix resin at high temperatures may cause the ultimate destruction of ICA interconnection, it is also meaningful to know how long ICA bonding can withstand a particular temperature before a certain amount of degradation occurs [3].

Thermal kinetics analysis is widely used in studying the curing, thermal decomposition, and flame retardancy of resins and has significant importance. In particular, 
theoretically, it can be applied to investigating the reaction mechanism of physical changes and chemical reactions; practically, it can provide design parameters for reactors. More importantly, it can be used to build the relationships among progress, time, and temperature, predict the shelf life for materials and products, estimate the decomposition of environmental pollutants, assess the risks, and provide the storage conditions for energetic materials [4-6]. Curing kinetics is a kind of phenomenological description of the reaction and is proven to be adequate to design and optimize a technical curing process or to investigate and differentiate the influences of resin/hardener types, catalysts, fillers, and additives, and thus is widely used [7-10]. The curing reaction of resin-based materials is an exothermic process and can be quantitatively studied by measuring the heat that is released, which is the foundation of curing kinetics analysis. With the thermal data tested by using a differential scanning calorimeter (DSC), a kinetic model of curing that describes the relationships among the curing degree, curing time, and temperature can be established through mathematical fitting. Moreover, glass transition temperature $\left(T_{g}\right)$ is an important index showing the heat resistance of a thermoset resin-based material, which indicates the integrity of a cured product at elevated temperatures. The correlation between $T_{g}$ and the curing degree is usually described by the DiBenedetto equation [11]. Consequently, the relationship between $T_{g}$ and the curing process can be established through the kinetic model of curing and the DiBenedetto equation, which means a time-temperature profile can be calculated for any $T_{g}$ requested. This prediction realizes the quantitative study on the relationships between performance and process, which is of great importance for the selection of cost-effective curing processes for an ideal $T_{g}$. Similarly, decomposition kinetics can be studied through dynamic thermogravimetric analysis (TGA) according to the Ozawa-Flynn-Wall method, and the resultant activation energy can be used for estimating the isothermal long-term stability (thermal endurance) of the material, e.g., at the operating temperature.

In this work, a series of thermal analyses were carried out on a self-made and commerce-oriented Ag-filled isotropic conductive adhesive (ICA) and its unfilled matrix resin [12], from which the curing and thermal decomposition behavior of the ICA and the matrix resin were well described by established mathematical models of kinetics. The relationship between glass transition temperature $\left(T_{g}\right)$ and the curing process (curing time and temperature) can be established through the kinetic model of curing and the DiBenedetto equations, which enables the design of the curing process of ICA for the expected $T_{g}$. An autocatalyzed kinetic model was used to describe the curing reaction, and the kinetic parameters were determined through the thermal data tested by DSC under isothermal conditions at 120,130 , and $140^{\circ} \mathrm{C}$ for $2 \mathrm{~h}$. Moreover, the thermal decomposition stability of the ICA and its unfilled matrix resin were also studied qualitatively and quantitatively through the thermal data tested by Simultaneous TGA-DSC (SDT) in dynamic mode with heating rates of $2,3,5$, and $8{ }^{\circ} \mathrm{C} / \mathrm{min}$ and a temperature range of between $250{ }^{\circ} \mathrm{C}$ and $520^{\circ} \mathrm{C}$, which is valuable for predicting the service life of the resin system at a specific temperature. The influences of the addition of micro-scale silver flakes on the curing and decomposition reaction can also be reflected by the various indices.

\section{Results and Discussions}

\subsection{Curing Kinetics}

The curing of resin-based materials is an exothermic reaction, and it can be quantitatively studied by measuring the heat released with DSC. It is known that the formation of each individual chemical link between molecules produces a certain amount of heat. As a result, the degree of cure (conversion) $\alpha$ can be experimentally determined as the ratio of the heat released at time $t$ to the total heat of reaction [13]:

$$
\alpha(t)=\frac{\text { partial heat of reaction }(t)}{\text { total heat of reaction }}
$$


However, this method only measures the relative conversion; it yields only a fraction of reacted groups out of reactive groups that could react within the topological and time constraints of the experiment. The absolute extent of reaction is defined as the fraction of reactive groups that have reacted. It is hardly possible to achieve true $100 \%$ chemical conversion in a thermosetting polymer formed by the polymerization of multifunctional monomers [14,15]. As the sterically hindered groups cannot react, the measured reaction heat shows only the reaction heat possible under the chosen conditions. It does not therefore correspond to the theoretical value expected from the stoichiometric composition and can vary depending on the measurement conditions. Even so, kinetic determination is useful because it shows the course of the conversion, i.e., how many of the reactive groups that can realistically react have already reacted [15].

The reaction rate $d \alpha / d t$ is a function of the conversion $f(\alpha)$ and is influenced by temperature $[13,15]$ :

$$
\frac{d \alpha}{d t}=k(T) f(\alpha)
$$

The temperature dependence of the reaction rate is described by the Arrhenius equation $[13,15]$ :

$$
k(T)=k_{0} e^{-E_{A} / R T}
$$

where $E_{A}$ is the activation energy, $R$ the gas constant, and $k_{0}$ the rate constant.

In the kinetic evaluations described in the following studies, the autocatalyzed kinetic model was used $[13,16]$, whereby

$$
\frac{d \alpha}{d t}=k(T) \alpha^{m}(1-\alpha)^{n}
$$

where $m$ and $n$ are the reaction orders.

For a reaction conducted at temperature (T), the autocatalytic rate in Equation (4) can be cast in its logarithmic form:

$$
\lg \left(\frac{d \alpha}{d t}\right)=\lg k(T)+m \lg (\alpha)+n \lg (1-\alpha)
$$

The reaction rate $d \alpha / d t$ and conversion $\alpha$ can be calculated from the thermal data tested by DSC. In order to avoid the errors caused by instrumental factors at the beginning and end of the reaction, only the data with conversion between 20 and $80 \%$ was taken into calculation. As a result, Equation (5) has the form $z=a+b x+c y$ and can be solved using multiple linear regression analysis.

The logarithm of the Arrhenius Equation (3) is

$$
\ln k(T)=\ln k_{0}-\frac{E_{A}}{R T}
$$

where $R$ is the gas constant and $R=8.314 \mathrm{~J} /(\mathrm{mol} \cdot \mathrm{K})$. With $k(T)$ under different isothermal temperatures calculated from Equation (3), a linear dependence exists between $\ln K(T)$ and $1 / T$ such that the slope of the plot provides the activation energy $E_{A}$.

All the kinetic parameters can be calculated using the above methods; thus, the kinetic model of curing, which can be used to describe the relationships among the curing degree, curing time, and temperature, can be established.

Figure 1 presents the isothermal DSC curves and conversion curves of the unfilled matrix resin and the Ag-filled ICA at different temperatures. The specific values obtained from the curves are provided in Table 1. As can be seen from the isothermal curves, the existence of slopes at front edges indicates the characteristic of the catalytic reaction mechanism of the systems. The addition of micro-scale silver flakes did not change the curing mechanism very much because their curves exhibit the same tendency as those of unfilled matrix resin. The heat flow of the Ag-filled ICA was much less than that of the unfilled matrix resin, which can be easily understood by the reduction in thermosetting resin contained in a unit mass of ICA. 
In addition, Table 1 also shows that the time when the system reached the highest reaction rate $t_{\max }$ of the ICA was less than that of the unfilled matrix resin. Moreover, with the increase in isothermal temperature, the slope becomes even steeper, $t_{\max }$ is shortened, the value of the corresponding reaction rate gets even higher, and the total enthalpy becomes greater.
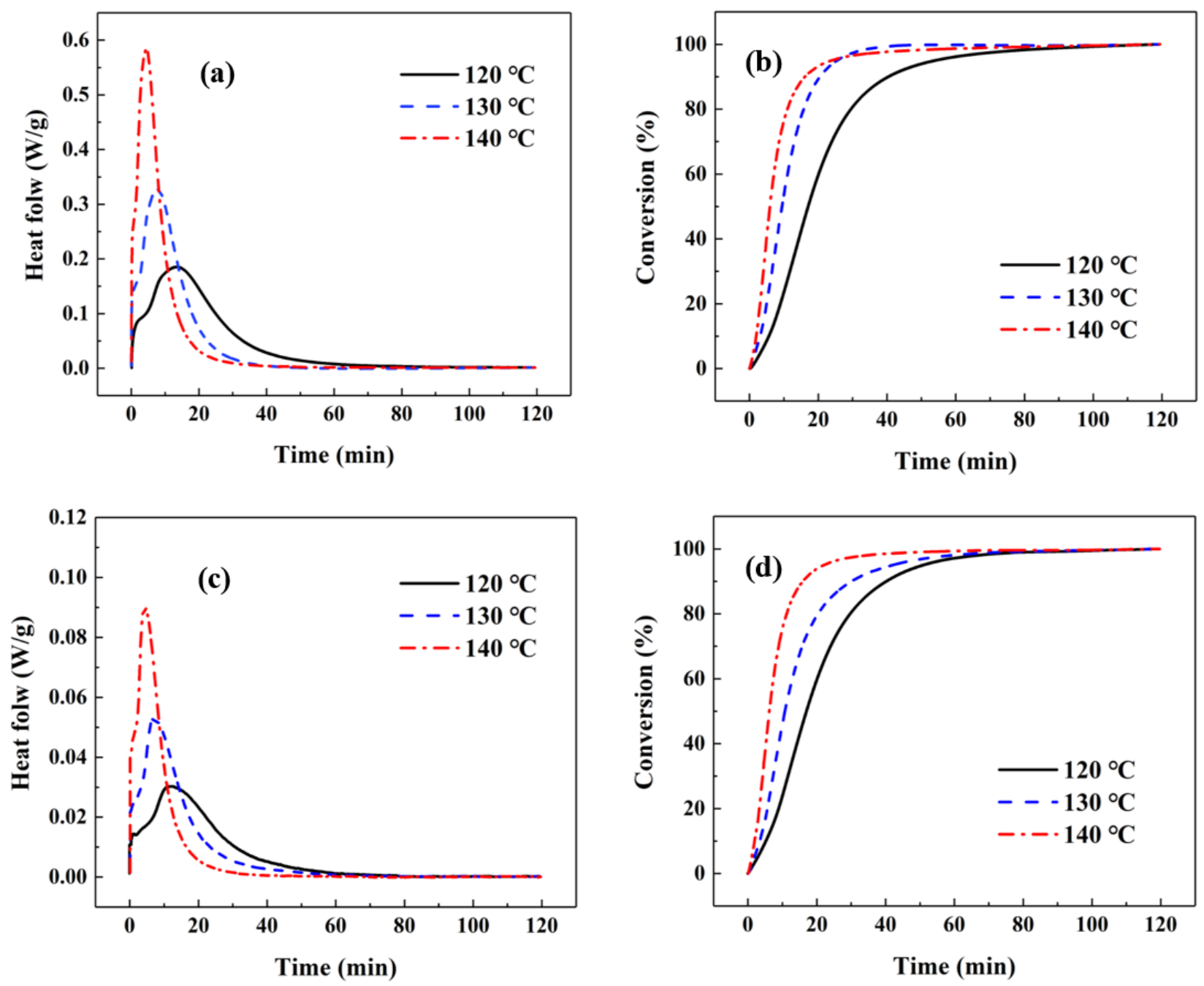

Figure 1. Isothermal DSC curves and conversion curves of the unfilled matrix resin $(\mathbf{a}, \mathbf{b})$ and the Ag-filled ICA (c,d).

Table 1. Isothermal data of the Ag-filled ICA and its unfilled matrix resin.

\begin{tabular}{cccc}
\hline Sample & $\boldsymbol{T}\left({ }^{\circ} \mathbf{C}\right)$ & $\boldsymbol{t}_{\max }(\mathbf{m i n})$ & Total Enthalpy $(\mathbf{J} / \mathbf{g})$ \\
\hline \multirow{3}{*}{ Unfilled matrix resin } & 120 & 13.5 & 281.1 \\
\cline { 2 - 4 } & 130 & 7.7 & 300.1 \\
\cline { 2 - 4 } & 140 & 4.5 & 320.7 \\
\hline \multirow{2}{*}{ Ag-filled ICA } & 120 & 11.9 & 52.3 \\
\cline { 2 - 4 } & 130 & 7.1 & 53.4 \\
\hline
\end{tabular}

Based on the above analysis, an autocatalyzed kinetic model was used to describe the curing reaction and the kinetic parameters were determined according to the method explained in the former section. The calculated kinetic parameters are listed in Table 2. The 
activation energy $E_{A}$ of the matrix resin was higher than that of the ICA, which means the curing process of ICA is easier to take place.

Table 2. Calculated curing kinetics parameters of the Ag-filled ICA and its matrix resin.

\begin{tabular}{|c|c|c|c|c|c|c|c|c|}
\hline Sample & $T\left({ }^{\circ} \mathrm{C}\right)$ & $k(T)\left(\min ^{-1}\right)$ & $n$ & $m$ & $\bar{n}$ & $\bar{m}$ & $E_{A}(\mathrm{~kJ} / \mathrm{mol})$ & $k_{0}\left(\mathrm{~s}^{-1}\right)$ \\
\hline \multirow{3}{*}{ Matrix resin } & 120 & 0.15 & 1.28 & 0.72 & \multirow{3}{*}{1.40} & \multirow{3}{*}{0.74} & \multirow{3}{*}{72.9} & \multirow{3}{*}{$1.24 \times 10^{7}$} \\
\hline & 130 & 0.26 & 1.38 & 0.75 & & & & \\
\hline & 140 & 0.45 & 1.54 & 0.74 & & & & \\
\hline \multirow{3}{*}{ ICA } & 120 & 0.20 & 1.54 & 0.91 & \multirow{3}{*}{1.71} & \multirow{3}{*}{0.94} & \multirow{3}{*}{68.1} & \multirow{3}{*}{$3.73 \times 10^{6}$} \\
\hline & 130 & 0.34 & 1.76 & 0.92 & & & & \\
\hline & 140 & 0.55 & 1.84 & 0.99 & & & & \\
\hline
\end{tabular}

Therefore, the model equation of the unfilled matrix resin and self-made ICA can be described as Equations (7) and (8), respectively:

$$
\begin{aligned}
& \frac{d \alpha}{d t}=1.24 \times 10^{7} e^{-8768.3 / T} \alpha^{0.74}(1-\alpha)^{1.4} \\
& \frac{d \alpha}{d t}=3.73 \times 10^{6} e^{-8191 / T} \alpha^{0.94}(1-\alpha)^{1.71}
\end{aligned}
$$

To verify the accuracy of the established equations, the tested and calculated curves of $d \alpha / d t$ (e.g., curing rate) versus $\alpha$ are compared in Figure 2, which shows a good consistency. The specific values obtained by the curves are provided in Table 3 . As can be seen from Figure 2, the curves are found to first increase and then decrease. Moreover, the maximum curing rates of the matrix resin and the Ag-filled ICA at different curing temperatures are similar. This is understandable because the curing begins with an autocatalytic reaction resulting in an induced reaction period of increasing reaction rate. As the reaction proceeds, molecular mobility is restricted, and the curing reaction becomes more and more diffusion controlled $[17,18]$. As a result, the reaction rate decreases to such an extent that the reaction practically stops. However, the conversion corresponding to the highest $d \alpha / d t$ (e.g., $\alpha_{\max }$ ) for the matrix resin was $\sim 36 \%$ and was $\sim 6 \%$ higher than that of the self-made ICA. This indicates that the addition of micro-scale silver flakes accelerates the transformation of the reaction mechanism from chemical reaction-controlled to diffusion-controlled, which can be attributed to the barrier effect of the silver flakes on the matrix resin.
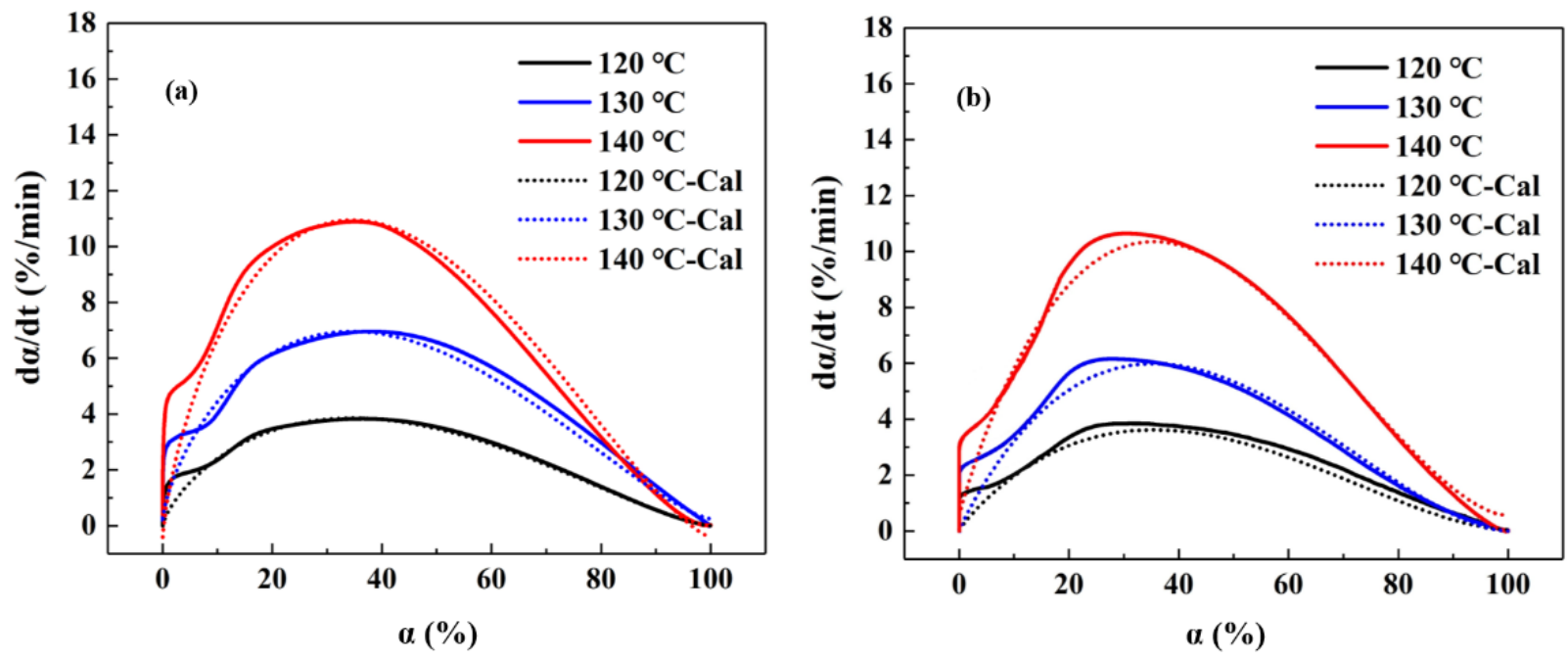

Figure 2. Curves of the relationships between $\mathrm{d} \alpha / \mathrm{dt}$ and $\alpha$, and comparison between the tested and calculated data: (a) unfilled matrix resin; (b) Ag-filled ICA. 
Table 3. Data obtained from the relationship between $d \alpha / d t$ and $\alpha$ as obtained in tests.

\begin{tabular}{cccc}
\hline Sample & $\boldsymbol{T}\left({ }^{\circ} \mathbf{C}\right)$ & $\boldsymbol{\alpha}_{\max }(\%)$ & $(\boldsymbol{d} \boldsymbol{\alpha} / \boldsymbol{d} \boldsymbol{t})_{\max }(\mathbf{\%} / \mathbf{m i n})$ \\
\hline \multirow{3}{*}{ Unfilled matrix resin } & 120 & 36.6 & 3.84 \\
\cline { 2 - 4 } & 130 & 37.9 & 6.96 \\
\cline { 2 - 4 } Ag-filled ICA & 140 & 35.0 & 10.89 \\
\cline { 2 - 4 } & 120 & 31.0 & 3.85 \\
\cline { 2 - 4 } & 130 & 28.4 & 6.16 \\
\hline
\end{tabular}

\subsection{Relationship between $T_{g}$ and the Curing Process}

The relationship between the degree of cure (or conversion) and the glass transition temperature can be described by model functions and their parameters determined by curve fitting, which allows the degree of cure to be determined in a routine analysis from the value of $T_{g}$.

The DiBenedetto equation is often used to describe the functional relationship between $T_{g}$ and $\alpha[19,20]$ :

$$
T_{g}=T_{g 0}+\frac{\lambda \alpha\left(T_{g 1}-T_{g 0}\right)}{1-(1-\lambda) \alpha}
$$

where $T_{g 0}$ and $T_{g 1}$ are the glass transition temperatures of the unreacted system and fully cured system, respectively; $\lambda$ is a fitting parameter between 0 and 1 , which is a structuredependent parameter.

For a partially cured material, the degree of cure is an important quality controlling parameter, and it can be determined according to the following equation:

$$
\alpha=1-\frac{\Delta H_{r}}{\Delta H_{0}}
$$

where $\Delta H_{0}$ is the enthalpy of the curing reaction of the pure unreacted system and $\Delta H_{r}$ is the specific enthalpy of the post-curing.

After isothermal treatments of the newly self-made ICA samples and their corresponding unfilled matrix resin at $100{ }^{\circ} \mathrm{C}$ for different times $(0,20,40,60,80$, and $180 \mathrm{~min})$, DSC tests were carried out on these samples from $-65^{\circ} \mathrm{C}$ to $300{ }^{\circ} \mathrm{C}$ at $10^{\circ} \mathrm{C} / \mathrm{min}$, and the results are shown in Figure 3 in which the series of curves clearly depicts how the exothermic post-curing peak height decreased with the increase in curing time. The corresponding glass transition temperature $T_{g}$ increased with longer reaction times but did not exceed $T_{g}$ of fully cured systems, i.e., $T_{g 1}\left(131.1^{\circ} \mathrm{C}\right.$ for the matrix resin and $111.6^{\circ} \mathrm{C}$ for the ICA were measured from the fully cured systems by DSC). Some important data calculated from the curves are listed in Table 4 with which the relationship between the degree of cure $\alpha$ and $T_{g}$ can be described by model functions and their parameters determined by curve fitting. Figure 4 exhibits the DiBenedetto equation fitting curves of the relationship between $\alpha$ and $T_{g}$ with high fitting accuracy. Values of $\lambda$ for the matrix resin and the self-made ICA were determined to be 0.40 and 0.27 , respectively.

As a result, the DiBenedetto equation of the unfilled matrix resin and the self-made ICA can be described by Equations (11) and (12), respectively:

$$
\begin{aligned}
& T_{g}=T_{g 0}+\frac{\lambda \alpha\left(T_{g 1}-T_{g 0}\right)}{1-(1-\lambda) \alpha}=-41.5+\frac{69.04 \alpha}{1-0.6 \alpha} \\
& T_{g}=T_{g 0}+\frac{\lambda \alpha\left(T_{g 1}-T_{g 0}\right)}{1-(1-\lambda) \alpha}=-38+\frac{40.39 \alpha}{1-0.73 \alpha}
\end{aligned}
$$



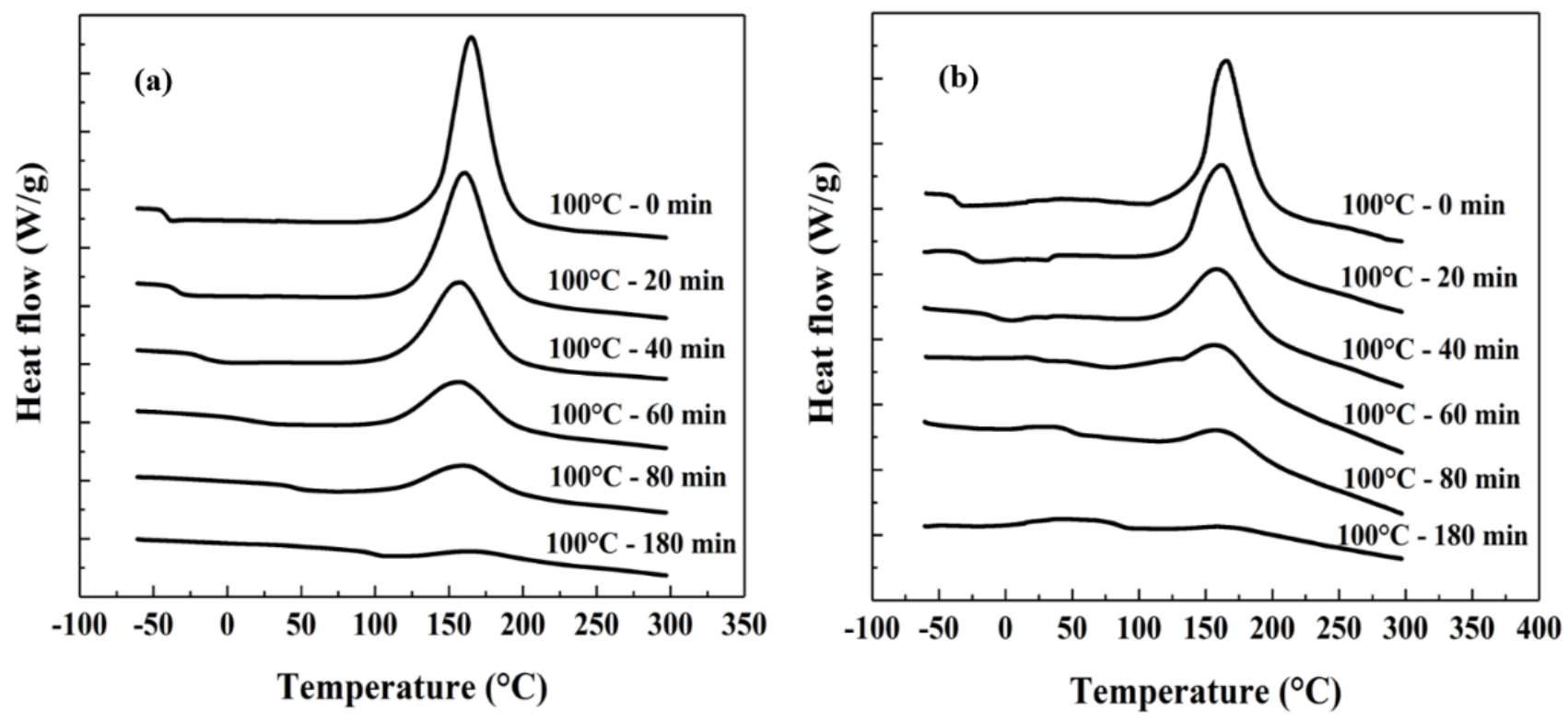

Figure 3. Post-curing curves of the unfilled matrix resin (a) and Ag-filled ICA (b) after being heated at $100{ }^{\circ} \mathrm{C}$ for different time periods.

Table 4. Measured curing kinetics parameters of the Ag-filled ICA and its matrix resin.

\begin{tabular}{|c|c|c|c|c|c|c|}
\hline \multirow[b]{2}{*}{$t$ (min) } & \multicolumn{2}{|c|}{$\Delta H r(\mathrm{~J} / \mathrm{g})$} & \multicolumn{2}{|c|}{$T_{g}\left({ }^{\circ} \mathrm{C}\right)$} & \multicolumn{2}{|c|}{$\alpha$} \\
\hline & $\begin{array}{c}\text { Unfilled } \\
\text { Matrix Resin }\end{array}$ & Ag-Filled ICA & $\begin{array}{c}\text { Unfilled } \\
\text { Matrix Resin }\end{array}$ & Ag-Filled ICA & $\begin{array}{c}\text { Unfilled } \\
\text { Matrix Resin }\end{array}$ & Ag-Filled ICA \\
\hline 0 & 346.8 & 46.6 & -41.5 & -38.0 & 0 & 0 \\
\hline 20 & 288.9 & 37.1 & -34.42 & -26.8 & 0.17 & 0.20 \\
\hline 40 & 226.5 & 22.2 & -16.82 & -7.9 & 0.35 & 0.52 \\
\hline 60 & 137.3 & 13.3 & 15.08 & 24.6 & 0.60 & 0.72 \\
\hline 80 & 104.7 & 7.7 & 46.16 & 49.4 & 0.70 & 0.84 \\
\hline 180 & 39.5 & 2.7 & 99.28 & 84.6 & 0.89 & 0.94 \\
\hline
\end{tabular}

With the DiBenedetto equations and kinetic curing models achieved, the relationship between $T_{g}$ and the curing process can be established, which means a time-temperature profile can be calculated for any $T_{g}$ requested. For the self-made ICA, its $T_{g}$ was required to be higher than $100{ }^{\circ} \mathrm{C}$ so as to ensure its normal functions. $\alpha$ was calculated to be 0.977 when $T_{g}=100{ }^{\circ} \mathrm{C}$, according to Equation (12). From the kinetic model in Equation (8) that describes the relationships among the curing degree, curing time, and temperature, the time-temperature profile of the ICA when $T_{g}=100^{\circ} \mathrm{C}$ can thus be calculated, as shown in Figure 5. This is of great importance for the selection of cost-effective curing processes for an ideal $T_{g}$. 

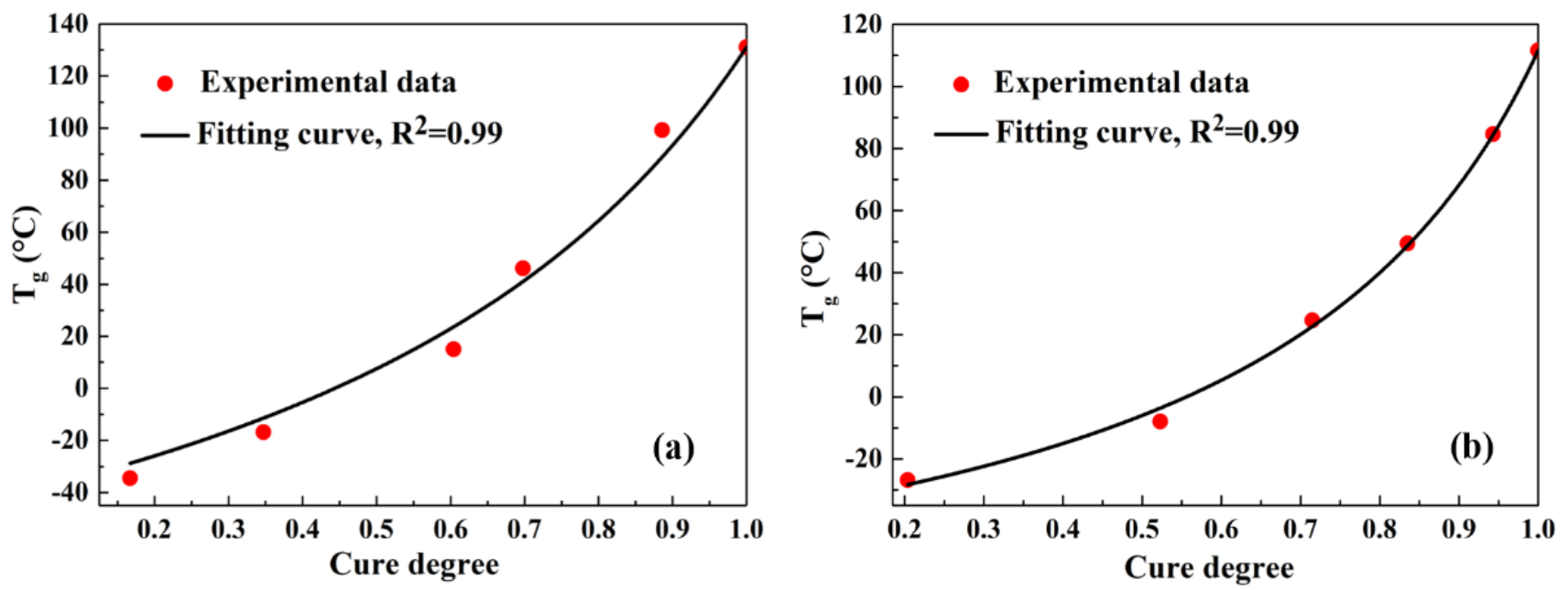

Figure 4. DiBenedetto equation fitting curves of the relationship between $\alpha$ and $T_{g}$ of (a) the unfilled matrix resin and (b) Ag-filled ICA.

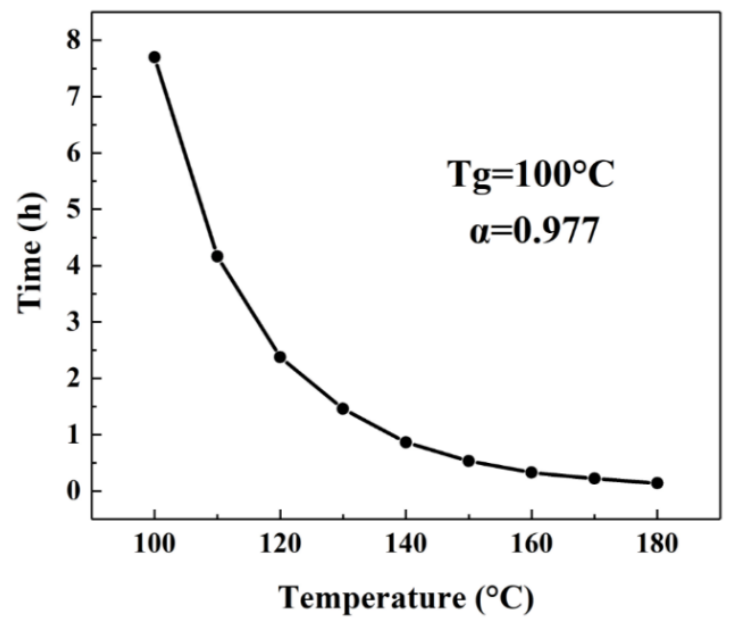

Figure 5. The predicted time-temperature profile of the Ag-filled ICA when $T_{g}=100{ }^{\circ} \mathrm{C}$.

\subsection{Decomposition Kinetics and Thermal Endurance}

The degradation process can be described by the following reaction:

$$
\mathrm{A}(\mathrm{s}) \rightarrow \mathrm{B}(\mathrm{s})+\mathrm{C}(\mathrm{g})
$$

The rate of conversion in decomposition, $d \alpha_{d} / d t$, is a linear function of a temperaturedependent reaction rate constant for a general type, which is the same as Equation (2). The reaction rate constant is usually described according to the Arrhenius equation, which is a function of temperature. As TGA tests were conducted with a constant heating rate $\beta$, the equations can be transformed as follows [15]:

$$
\begin{aligned}
& \frac{d \alpha_{d}}{d t}=\frac{d \alpha_{d}}{d T} \frac{d T}{d t}=\beta \frac{d \alpha_{d}}{d T} \\
& \frac{d \alpha_{d}}{d T}=\frac{A}{\beta} e^{-E_{A}^{\prime} / R T} f\left(\alpha_{d}\right)
\end{aligned}
$$

where $E_{A}^{\prime}$ is the activation energy and $A$ is the rate constant. 
The conversion at time $t, \alpha_{d}(t)$, can be calculated by the ratio of the mass of volatiles produced to the total volatile produced at the end of the pyrolysis reaction [15]:

$$
\alpha_{d}(t)=\frac{M_{0}-M_{t}}{M_{0}-M_{f}}
$$

where $M_{0}, M_{t}$, and $M_{f}$ are the initial mass of sample, the mass at time $t$, and the final mass remaining at the end of pyrolysis process, respectively.

In this study, the Ozawa-Flynn-Wall method with relatively higher reliability was used for kinetic analysis of the pyrolysis process, and the reaction mechanism did not need to be considered.

The Ozawa-Flynn-Wall method is proposed by the following equation [21,22]:

$$
\lg \beta=\lg \frac{A E_{A}^{\prime}}{R g\left(\alpha_{d}\right)}-2.315-\frac{0.457 E_{A}{ }^{\prime}}{R T}
$$

where $g\left(\alpha_{d}\right)=\int \frac{d \alpha_{d}}{f\left(\alpha_{d}\right)}$ is the integrated form of the conversion dependence function $f\left(\alpha_{d}\right)$, another function which is only related to $\alpha_{d}$. As a result, $E_{A}^{\prime}$ can be obtained from the linear correlation of $\lg (\beta)$ versus $1 / T$ at each degree of conversion.

The activation energy calculated above is the parameter necessary to determine the lifetime as a function of the isothermal temperature according to ASTM E1877 "Standard Practice for Calculating Thermal Endurance of Materials from Thermogravimetric Decomposition Data" [23].

Figure 6 presents the curves of thermogravimetric analysis (TGA) and derivative thermogravimetric analysis (DTGA) of the unfilled matrix resin and Ag-filled ICA; some specific data achieved from the curves are listed in Table 5. The mass loss occurred in the range of $250 \sim 520^{\circ} \mathrm{C}$. The mass curves shift to higher temperature regions when increasing the heating rate from 2 to 3,5 , and $8{ }^{\circ} \mathrm{C} / \mathrm{min}$, especially in the range of $350 \sim 450{ }^{\circ} \mathrm{C}$. The maximum decomposition rate also increased with the increasing heating rate. This is because a high heating rate often causes a reaction hysteresis phenomenon [24] and leads to an increase in temperature gradients within the samples [15]. The total mass loss of the unfilled matrix resin was around $86 \%$ while that of the Ag-filled ICA was about 14\% due to the existence of silver filler. Both the unfilled matrix resin and Ag-filled ICA showed a well-defined decomposition profile, namely a smooth and continuous mass change with a single maximum change, which indicates that the addition of micro-scale silver flakes does not change the decomposition mechanisms by much. However, it should be noted in Table 5 that $T_{\mathrm{M}}$ (i.e., the temperature when the decomposition rate reaches the maximum value) of the Ag-filled ICA was lower than that of the unfilled matrix resin with the same heating rate, which implies that the ICA decomposes more than the matrix resin at the same temperature. For each of the thermal curves obtained at different heating rates in Figure $2 \mathrm{a}, \mathrm{c}$, the absolute temperatures at conversions $\alpha_{d}=5 \%, 8 \%, 10 \%$, and $15 \%$ were determined. Therefore, the activation energy for the thermal decomposition of the Ag-filled ICA and the unfilled matrix resin was calculated to be $134.1 \mathrm{~kJ} / \mathrm{mol}$ and $152.7 \mathrm{~kJ} / \mathrm{mol}$, respectively, using the Ozawa-Flynn-Wall method, which means the decomposition of the Ag-filled ICA is easier to occur than that of the unfilled matrix resin. The reason behind this is assumed to be the lower crosslinking degree of the Ag-filled ICA than the unfilled matrix resin due to the cut-off effect of the flakes on the polymer matrix. 

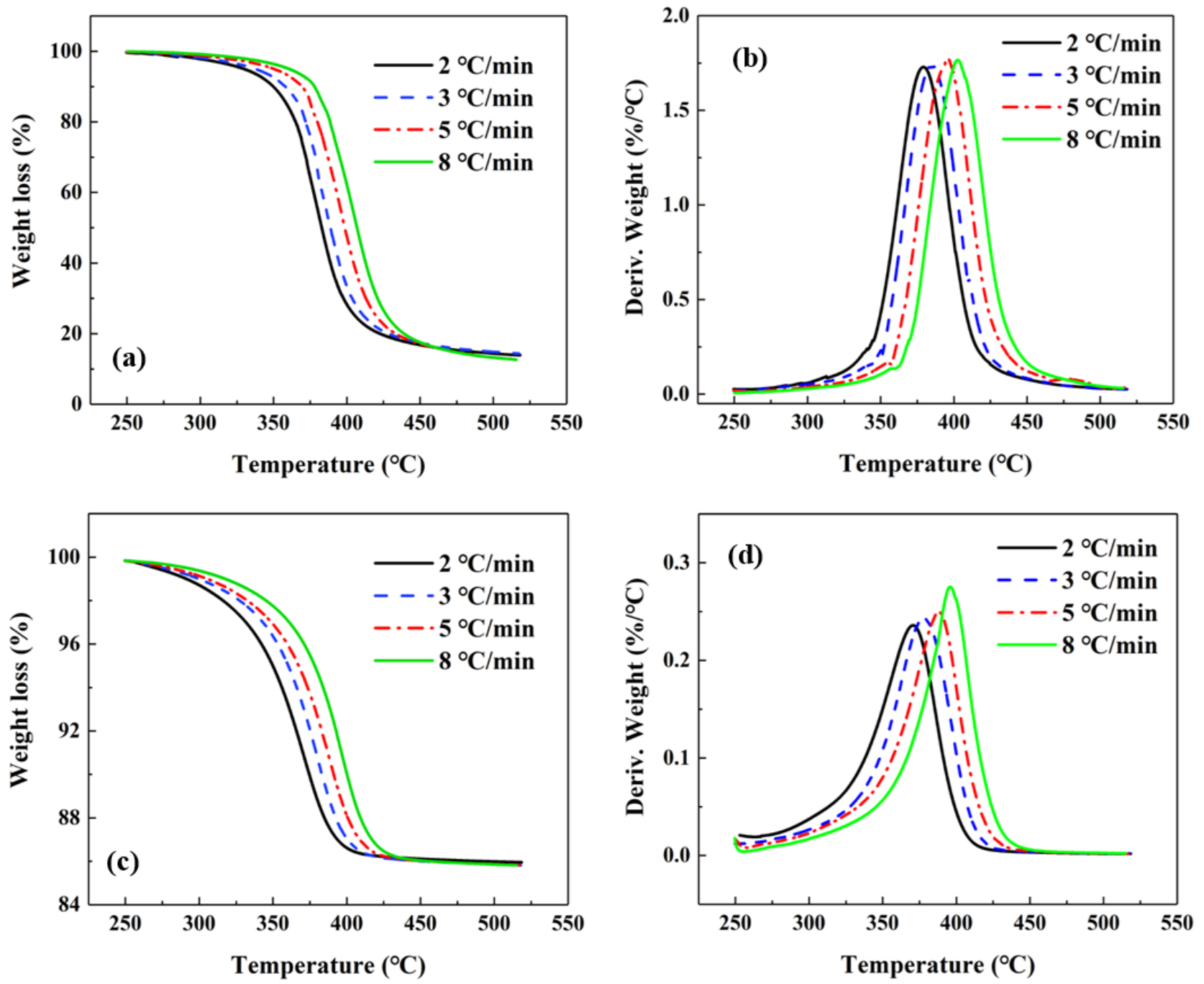

Figure 6. Thermogravimetric (TG) curves of the unfilled matrix resin (a) and their corresponding derivative thermogravimetric (DTG) curves (b); TG curves of the self-made ICA (c) and their corresponding DTG curves of the ICA $(\mathbf{d})$.

Table 5. Calculated decomposition kinetic parameters of the Ag-filled ICA and its unfilled matrix resin.

\begin{tabular}{|c|c|c|c|c|c|c|c|c|c|}
\hline \multirow[b]{2}{*}{ Sample } & \multicolumn{4}{|c|}{$T_{\mathrm{M}}\left({ }^{\circ} \mathrm{C}\right)$} & \multicolumn{4}{|c|}{ Weight Loss (\%) } & \multirow{2}{*}{$\begin{array}{c}E_{A} \\
(\mathrm{KJ} / \mathrm{mol})\end{array}$} \\
\hline & $\begin{array}{c}2 \\
{ }^{\circ} \mathrm{C} / \mathrm{min}\end{array}$ & $\begin{array}{c}3 \\
{ }^{\circ} \mathrm{C} / \mathrm{min}\end{array}$ & $\begin{array}{c}5 \\
{ }^{\circ} \mathrm{C} / \mathrm{min}\end{array}$ & $\begin{array}{c}8 \\
{ }^{\circ} \mathrm{C} / \mathrm{min}\end{array}$ & $\begin{array}{c}2 \\
{ }^{\circ} \mathrm{C} / \mathrm{min}\end{array}$ & $\begin{array}{c}3 \\
{ }^{\circ} \mathrm{C} / \mathrm{min}\end{array}$ & $\begin{array}{c}5 \\
{ }^{\circ} \mathrm{C} / \mathrm{min}\end{array}$ & $\begin{array}{c}8 \\
{ }^{\circ} \mathrm{C} / \mathrm{min}\end{array}$ & \\
\hline $\begin{array}{c}\text { Unfilled } \\
\text { matrix resin }\end{array}$ & 379.2 & 384.8 & 395.5 & 402.8 & 85.7 & 85.5 & 87.1 & 87.3 & 152.7 \\
\hline $\begin{array}{l}\text { Ag-filled } \\
\text { ICA }\end{array}$ & 370.8 & 378.0 & 388.0 & 396.1 & 13.9 & 14.0 & 14.0 & 14.0 & 134.1 \\
\hline
\end{tabular}

The activation energy calculated above is the parameter necessary to determine the lifetime as a function of the isothermal temperature of use according to ASTM E1877 Standard (see Figure 7 below, the iso-conversion plots of the unfilled resin matrix (a) and the Ag-filled ICA (b)). In this case, the lifetime was calculated on the assumption that the decomposition reaches $0.1 \%, 0.5 \%$, and $1 \%$. The thermal stability of the matrix resin was found to be better than that of the ICA. 

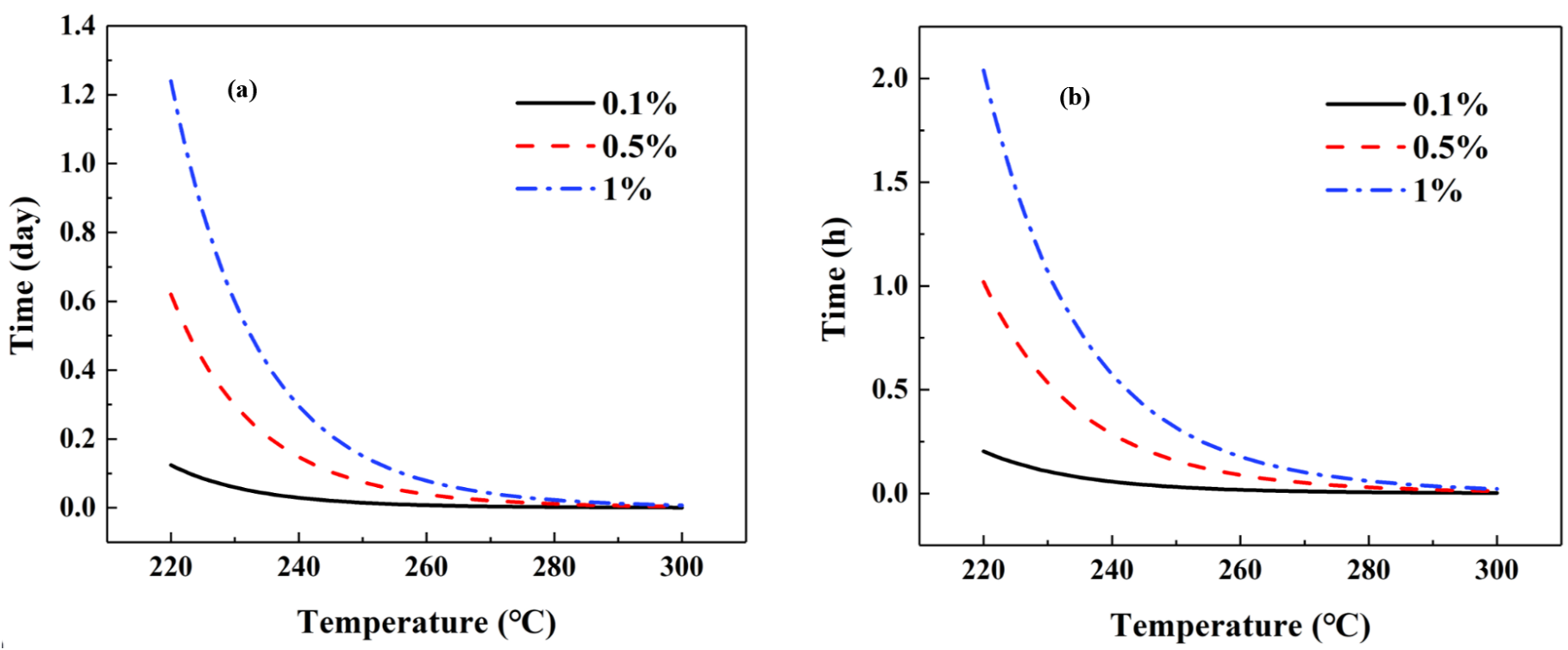

Figure 7. Predicted iso-conversion plots of the unfilled matrix resin (a) and Ag-filled ICA (b).

\section{Materials and Methods}

\subsection{Materials and Sample Preparation}

The process for preparation of the matrix resin mainly included two steps. The first step was to mix the epoxy binder (bisphenol F diglycidyl ether, BFDGE), curing agent (methylhexahydrophthalic anhydride, MHHPA), coupling agent ( $\gamma$-glycidyl ether oxypropyltrimethoxysilane), and anti-settling agent (fumed silica) proportionally to achieve mixture A. The second step was the further incorporation of curing accelerant (1-cyanoethyl2-ethyl-4-methylimidazole, 2E4MZ-CN), antifoaming agent (modified polysiloxane solution) and antioxidant (isooctyl 3,5-di-tert-butyl-4-hydroxyphenylpropionate) into mixture A proportionally, followed by stirring thoroughly to obtain the unfilled matrix resin. For the fabrication of ICA, the specified amount of silver flakes (mean diameter $5.2 \mu \mathrm{m}$ ) was added to the matrix resin and the mixture was uniformly blended using an automatic planetary gravity mixer (RM300SA, Sinomix, Mianyang, China). The percentage of conductive filler in the ICA was 81.76 wt.\%.

\subsection{Test Method}

The curing of resin-based materials was an exothermic reaction and could be quantitatively studied by measuring the heat released with DSC. Moreover, the physical properties of a thermoset such as the specific heat capacity change noticeably when glass transition occurs, which means the glass transition temperature $\left(T_{g}\right)$ could also be measured using DSC (Q200, TA Instruments). For the study of curing kinetics, the runs were performed in isothermal mode at 120,130 , and $140^{\circ} \mathrm{C}$ for $2 \mathrm{~h}$. In total, $6 \sim 7 \mathrm{mg}$ newly made samples filled in aluminum pans with pierced lids were tested, and the atmosphere was nitrogen (50 $\mathrm{mL} / \mathrm{min}$ ). For the determination of $T_{g}$, tests were conducted in dynamic mode with a heating rate of $10{ }^{\circ} \mathrm{C} / \mathrm{min}$ and a temperature range between $-65^{\circ} \mathrm{C}$ and $300{ }^{\circ} \mathrm{C}$. In total, 5 10 $\mathrm{mg}$ samples filled in aluminum pans with pierced lids were tested, and the atmosphere was nitrogen $(50 \mathrm{~mL} / \mathrm{min})$. The reaction progress of thermal decomposition could be indicated by the mass loss, thus for the study of decomposition kinetics, parameters could be calculated through dynamic TGA measurements (SDT Q600, TA Instruments) according to the Ozawa-Flynn-Wall method. Tests were performed in dynamic mode with heating rates of $2,3,5$, and $5 \mathrm{~K} / \mathrm{min}$ and a temperature range between $250{ }^{\circ} \mathrm{C}$ and $520{ }^{\circ} \mathrm{C}$. In total, 20 22 mg fully cured samples filled in alumina pans without lids were tested, and the atmosphere was nitrogen $(50 \mathrm{~mL} / \mathrm{min})$. 


\section{Conclusions}

In this work, a series of thermal analyses were carried out on a self-made and commerce-oriented Ag-filled isotropic conductive adhesive (ICA) and its unfilled matrix resin, from which, the curing and thermal decomposition behavior of the ICA and the matrix resin were well described by the established mathematical models of kinetics. The relationship between glass transition temperature $\left(T_{g}\right)$ and curing process (time and temperature) could be established through the kinetic model of curing and the DiBenedetto equation, which enabled the design of the curing process of ICA for the expected $T_{g}$. Furthermore, the thermal decomposition stability of the Ag-filled ICA and its unfilled matrix resin were also qualitatively and quantitatively studied and were proven to be valuable for predicting the service life of the resin system at a specific temperature. The main conclusions can be drawn as follows:

(1) The curing behaviors of both the Ag-filled ICA and its unfilled matrix resin exhibited the characteristics of a catalytic reaction mechanism, which means the addition of micro-scale silver flakes did not change the curing mechanisms by much. However, the addition of micro-scale silver flakes accelerated the transformation of the reaction mechanism from chemical reaction-controlled to diffusion-controlled.

(2) The curing activation energy of the unfilled matrix resin was $72.9 \mathrm{~kJ} / \mathrm{mol}$, higher than that of the Ag-filled ICA $(68.1 \mathrm{~kJ} / \mathrm{mol})$, which indicates the curing process of Ag-filled ICA was easier to take place. The tested and calculated data were compared to verify the accuracy of the established kinetic equations, which showed a good consistency.

(3) The activation energy for the thermal decomposition of the ICA and the matrix resin were calculated to be $134.1 \mathrm{~kJ} / \mathrm{mol}$ and $152.7 \mathrm{~kJ} / \mathrm{mol}$, respectively, using the OzawaFlynn-Wall method, which means the decomposition of the ICA was easier to occur than that of the matrix resin.

Author Contributions: Conceptualization, H.J., M.Z. and X.Z.; methodology, H.J. and M.Z.; software, H.J.; validation, H.J., M.Z. and X.Z.; formal analysis, H.J. and M.Z.; investigation, H.J. and M.Z.; resources, M.Z. and X.Z.; data curation, H.J.; writing—original draft preparation, H.J.; writing—review and editing, M.Z. and X.Z.; visualization, M.Z.; supervision, M.Z. and X.Z.; project administration, M.Z.; funding acquisition, M.Z. and X.Z. All authors have read and agreed to the published version of the manuscript.

Funding: This research is supported by the National Natural Science Foundation of China under Grant Nos. 51775195, 51405162, and 51565024, the Research Fund for the Science and Technology Planning Project of Guangdong Province under Grant Nos. 2014A010105023 and 2016A010103010, the Research Fund for the Science and Technology Planning Project of Guangzhou City under Grant No. 201807010028, and the Fundamental Research Fund for the Central Universities (SCUT-2017ZD038).

Data Availability Statement: Not applicable.

Conflicts of Interest: The funders had no role in the design of the study; in the collection, analyses, or interpretation of data; in the writing of the manuscript, or in the decision to publish the results.

\section{References}

1. Yim, M.J.; Li, Y.; Moon, K.-S.; Paik, K.W.; Wong, C.P. Review of Recent Advances in Electrically Conductive Adhesive Materials and Technologies in Electronic Packaging. J. Adhes. Sci. Technol. 2008, 22, 1593-1630. [CrossRef]

2. Chan, Y.C.; Uddin, M.A.; Alam, M.O.; Han, H.P. Curing kinetics of anisotropic conductive adhesive film. J. Electron. Mater. 2003, 32, 131-136. [CrossRef]

3. Cui, H.W.; Jiu, J.T.; Sugahara, T.; Nagao, S.; Suganuma, K.; Uchida, H.; Schroder, K.A. Using the Friedman method to study the thermal degradation kinetics of photonically cured electrically conductive adhesives. J. Therm. Anal. Calorim. 2015, 119, 425-433. [CrossRef]

4. Wang, X.; Wu, J.; Li, Y.; Zhou, C.; Xu, C. Pyrolysis kinetics and pathway of polysiloxane conversion to an amorphous SiOC ceramic. J. Therm. Anal. 2014, 115, 55-62. [CrossRef]

5. Carmona, V.B.; Campos, A.D.; Marconcini, J.M.; Mattoso, L.H.C. Kinetics of thermal degradation applied to biocomposites with TPS, PCL and sisal fibers by non-isothermal procedures. J. Therm. Anal. Calorim. 2014, 115, 153-160. [CrossRef] 
6. Künzel, M.; Yan, Q.-L.; Šelešovský, J.; Zeman, S.; Matyáš, R. Thermal behavior and decomposition kinetics of ETN and its mixtures with PETN and RDX. J. Therm. Anal. 2014, 115, 289-299. [CrossRef]

7. Baby, M.; Pal, R.; Francis, N.; Sudhi, S. Novolac epoxy resin from 4,4'-dihydroxybenzophenone: Thermal, thermomechanical, interfacial, and cure kinetics with DGEBA/DICY blend. J. Appl. Polym. Sci. 2018, 135, 46164. [CrossRef]

8. Qi, Y.; Weng, Z.; Wang, J.; Zhang, S.; Zong, L.; Liu, C.; Jian, X. A novel bio-based phthalonitrile resin derived from catechin: Synthesis and comparison of cur-ing behavior with petroleum-based counterpart. Polym. Int. 2018, 67, 322-329. [CrossRef]

9. Cui, H.W.; Suganuma, K.; Uchida, H. Using the Ozawa method to study the thermally initiated curing kinetics of vinyl ester resin. RSC Adv. 2014, 5, 2677-2683. [CrossRef]

10. Pongsa, U.; Samthong, C.; Praserthdam, P.; Somwangthanaroj, A. Influence of diaminobenzoyl-functionalized multiwalled carbon nanotubes on the nonisothermal curing kinetics, dynamic mechanical properties, and thermal conductivity of epoxy-anhydride composites. J. Appl. Polym. Sci. 2016, 133, 43567. [CrossRef]

11. Li, Q.; Li, X.; Meng, Y. Curing of DGEBA epoxy using a phenol-terminated hyperbranched curing agent: Cure kinetics, gelation, and the TTT cure diagram. Thermochim. Acta 2012, 549, 69-80. [CrossRef]

12. Jiang, H.; Zhou, M.B.; Zhu, J.F.; Zhang, X.P. Preparation of core-shell structured $\mathrm{SiO}_{2} @ \mathrm{Ag}$ spheres and their role in improving micro-sized Ag flake filled electrically conductive adhesive for LED packaging. In Proceedings of the 18th International Conference on Electronic Packaging Technology, Harbin, China, 16-19 August 2017; pp. 1607-1611.

13. Hutchinson, J.M.; Moradi, S. Thermal conductivity and cure kinetics of epoxy-boron nitride composites-A Review. Materials 2020, 13, 3634. [CrossRef] [PubMed]

14. Li, C.; Strachan, A. Molecular scale simulations on thermoset polymers: A review. J. Polym. Sci. Part B Polym. Phys. 2015, 53, 103-122. [CrossRef]

15. Riesen, R. Collected Applications of Thermal Analysis Thermosets; Mettler Toledo: Schwerzenbach, Switzerland, 2006.

16. Kim, Y.C.; Hong, S.; Sun, H.; Kim, M.G.; Choi, K.; Cho, J.; Choi, H.R.; Koo, J.C.; Moon, H.; Byun, D.; et al. UV-curing kinetics and performance development of in situ curable 3D printing materials. Eur. Polym. J. 2017, 93, 140-147. [CrossRef]

17. Turi, E.A. Thermal Characterization of Polymeric Materials; Academic Press: New York, NY, USA, 1981.

18. Wang, Q.; Zhang, S.; Liu, G.; Lin, T.; He, P. The mixture of silver nanowires and nanosilver-coated copper micronflakes for electrically conductive adhesives to achieve high electrical conductivity with low percolation threshold. J. Alloys Compd. 2020, 820, 153184. [CrossRef]

19. DiBenedetto, A.T. Prediction of the glass transition temperature of polymers: A model based on the principle of corresponding states. J. Polym. Sci. Part B Polym. Phys. 1987, 25, 1949-1969. [CrossRef]

20. Pascault, J.P.; Williams, R.J.J. Glass transition temperature versus conversion relationships for thermosetting polymers. J. Polym. Sci. Part B Polym. Phys. 1990, 28, 85-95. [CrossRef]

21. Popescu, C. Integral method to analyze the kinetics of heterogeneous reactions under non-isothermal conditions A variant on the Ozawa-Flynn-Wall method. Thermochim. Acta 1996, 285, 309-323. [CrossRef]

22. Mothé Cheila, G.; Iara, C.M. Study of kinetic parameters of thermal decomposition of bagasse and sugarcane straw using Friedman and Ozawa-Flynn-Wall isoconversional methods. J. Therm. Anal. Calorim. 2013, 113, 497-505. [CrossRef]

23. ASTM E1877; Standard Practice for Calculating Thermal Endurance of Materials from Thermogravimetric Decomposition Data. ASTM International: West Conshohocken, PA, USA, 2000.

24. Yamaguchi, M. Thermal Hysteresis Involving Reversible Self-Catalytic Reactions. Accounts Chem. Res. 2021, 54, 2603-2613. [CrossRef] [PubMed] 